\title{
Enquadramentos midiáticos de Lula na imprensa francesa: uma análise do Le Monde e Le Figaro
}

\author{
Anita Gonçalves Hoffmann \& Luís Mauro Sá Martino \\ Faculdade Cásper Líbero \\ E-mail: anita.hoffmannl@gmail.com/lmsamartino@gmail.com
}

\begin{abstract}
Resumo
Este trabalho analisa os enquadramentos midíaticos construídos pelos jornais Le Monde e Le Figaro em relação ao envolvimento do ex-presidente do Brasil Luiz Inácio Lula da Silva na Operação Lava Jato, investigação de ampla repercussão nacional e internacional. A partir da seleção e análise de 32 matérias

publicadas no site dos veículos franceses, sugere-se que os enquadramentos dados a Lula remetem ao sucesso de seus dois mandatos como Chefe de Estado e à sua personalidade. No entanto, os títulos das matérias apresentam enquadramentos negativos em relação ao conteúdo apresentado nos textos.
\end{abstract}

Palavras-chave: enquadramentos; política; Operação Lava Jato; Lula.

\begin{abstract}
This paper analyses the media news frames by the French newspapers Le Monde and Le Figaro about Brazil's former president Luiz Inácio Lula da Silva in the Lava Jato investigation. The analysis of 32 ar-

constantly framed as a successful in his two terms as president and to his personality. However, the titles frames are more negative than the content of the texts.
\end{abstract} ticles published by the papers suggests that Lula is

Keywords: framing; politics; Lava Jato Operation; Lula.

Data de submissão: 31/05/2017. Data de aprovação: 30/06/2017.

A Revista Estudos em Comunicação é financiada por Fundos FEDER através do Programa Operacional Factores de Competitividade - COMPETE e por Fundos Nacionais através da FCT - Fundação para a Ciência e a Tecnologia no âmbito do projeto Comunicação, Filosofia e Humanidades (LabCom.IFP) UID/CCI/00661/2013.
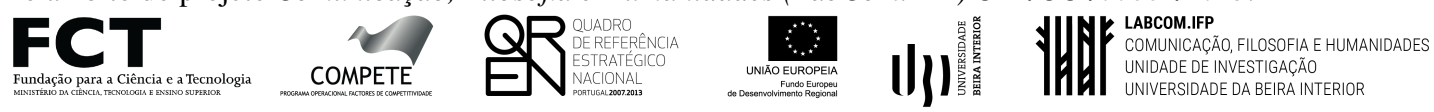


\section{Introdução}

STUDos sobre produção da notícia, sob um ponto de vista do construtivismo social (Berger; Luckmann, 1983), tendem a destacar a ideia de que todo relato de um fato é necessariamente uma exclusão premeditada de elementos da realidade com vistas a permitir sua narração e veiculação. Não há fato dado, mas como construção decorrente de critérios utilizados para se definir o que, diante da pluralidade de acontecimentos, será entendido como "fato jornalístico". Trazse não apenas "pontos de vista" diferentes mas, sobretudo, acionam-se perspectivas cognitivas responsáveis por indicar a "realidade" mostrada em um fato.

O objetivo deste artigo é compreender os enquadramentos midiáticos presentes na cobertura da "Operação Lava Jato", ação da Polícia Federal brasileira que investiga denúncias de corrupção em diversos âmbitos e setores do país. Em termos específicos, o texto questiona os enquadramentos do ex-presidente Luís Inácio Lula da Silva nas notícias sobre a Lava Jato veiculadas na imprensa francesa.

O nome da Operação Lava Jato remete ao seu momento inicial, em março de 2014, quando foi investigada uma rede de postos de combustíveis e lava-rápidos. Ao longo das 41 fases da Operação, deflagradas até julho de 2017, descobriu-se o envolvimento de vários empresários de grandes companhias, doleiros e políticos de diversos partidos, o que deu forças para que o escândalo deixasse o âmbito judiciário e se tornasse também midiático (Thompson, 2002).

A opção pela observação da cobertura internacional se deve, em primeiro lugar, à possibilidade de compreender como a imagem de uma figura política brasileira é apresentada no exterior - neste caso, no universo francófono.

Foram analisadas 32 matérias relacionadas à Operação Lava Jato publicadas nos sites dos jornais franceses Le Monde (25 matérias) e Le Figaro (7 matérias) entre março de 2014, quando a Operação começou, e julho de 2017, época que coincide com a divulgação da condenação de Lula em primeira instância pelo juiz Sergio Moro, responsável pela Lava Jato. Escolhemos para a análise textual apenas as matérias nas quais o nome do ex-presidente Lula tem destaque no título.

As matérias dos dois veículos franceses são produzidas por correspondentes alocados no Brasil ou jornalistas das redações parisienses dos jornais, mas também há conteúdos de agências internacionais, como a Associated Press, AFP e Reuters.

Discutindo a análise de enquadramento como prática metodológica, David, Atun e Monterola (2011) indicam como diferentes métodos levam a inferências semelhantes a respeito do que está sendo dito. A análise de enquadramento oferece a oportunidade de verificar a metacomunicação - os "quadros de sentido" - existente por trás de uma determinada cobertura a partir de indícios observados no próprio texto.

\section{Enquadramentos da Política}

A construção da realidade de um fato decorre, em boa medida, dos critérios utilizados para interpretá-lo e para lhe conferir um sentido, definindo-o desta ou daquela maneira Goffman (1974) sugere que esses enquadramentos são cruciais na maneira de "fazer ver" um determinado aconte- 
cimento ou fato, permitindo ao participante se situar em um determinado contexto e, a partir disso, agir.

A origem do conceito de enquadramento pode ser encontrada em Goffman (1974), na definição de enquadramentos como proposta de interpretação da realidade. De caráter intersubjetivo e construídos socialmente, os enquadramentos permitem atribuir sentido a eventos e situações cotidianas. Para Goffman, enquadramentos são protocolos de leitura empregados para tornar social e subjetivamente intelegível um determinado acontecimento.

Lecheler e De Vreese (2011, p. 959) definem enquadramentos como os "modelos de interpretação usados para classificar informações de modo a fazerem sentido e para serem processadas de maneira eficiente". Mais adiante (2011, p.960), indicam que os quadros "destacam alguns aspectos da realidade e deixam outros como pano de fundo; eles tem uma função seletiva".

Algo semelhante é afirmado por Coleman, Thorson e Wilkins (2011) ao indicar como isso tende a "obscurecer" determinados pontos da cobertura em relação aos outros. A seletividade, componente fundamental de qualquer processo de construção da notícia, está diretamente ligada à especificação de um quadro a partir do qual não só a mensagem é transmitida, mas, principalmente, lida.

Entman (1994) dedicou-se a estudar como funcionam os enquadramentos da mídia. Para ele, enquadrar significa selecionar aspectos de uma realidade e torná-los mais salientes em um texto, empregando, em certos casos, avaliações de caráter moral e oferecendo recomendações de tratamento para o evento em questão. Entman considera que os enquadramentos têm papel crucial nas formas como as elites políticas procuram controlar a percepção de determinados eventos ou assuntos e defende que eles estão presentes em todos os processos comunicativos.

Menashe e Siegel (1998) observam que o enquadramento é uma espécie de "metacomunicação" que define o que será comunicado na sequência de uma série de mensagens. O sentido da próxima informação recebida é estipulado pelo enquadramento metacomunicacional prévio, responsável por estabelecer o que está acontecendo e por indicar os modos de agir ou de compreender compatíveis com uma dada situação.

O enquadramento de uma notícia, nesse sentido, parece se estabelecer como uma inferência a ser feita a partir do conteúdo, mas não é necessariamente visível em um primeiro momento: é na observação dos direcionamentos, indicações léxicas, referências, proximidades e distanciamentos semânticos que o enquadramento - como parâmetro metacomunicacional - se revela.

Porto (2004) distingue dois tipos de enquadramento aplicados na análise da cobertura midiática. Os enquadramentos noticiosos são utilizados por jornalistas para organizar seus relatos, como padrões de apresentação, seleção e ênfase, ou seja, representam os pontos de vista adotados pelo texto para destacar elementos de uma realidade em detrimento de outros. Já os enquadramentos interpretativos promovem uma avaliação particular de temas ou eventos políticos e geralmente são elaborados por outros atores, como representantes do governo, partidos políticos, movimentos sociais, associações profissionais e especialistas, e incluídos no texto jornalístico.

Embora os jornalistas também contribuam com seus próprios enquadramentos interpretativos ao produzir notícias, esse tipo de enquadramento tem origem, geralmente, em atores sociais e políticos externos à prática jornalística (Porto, 2004, p. 92). 
Ao dedicar especial atenção ao modo como se compreende a realidade, o modelo proposto por Goffman (1974) sugere que o entendimento de um fato, de certa maneira, precede um conhecimento delineado e detalhado do que aconteceu. De acordo com Lecheler et al. (2015), uma das particularidades da noção de enquadramento leva em conta a repetição sistemática dos fatos.

A perspectiva do enquadramento procura mostrar que situações são definidas pelos participantes a partir de conhecimentos prévios, expectativas, associações anteriores e outros critérios a partir dos quais é possível entender o que se passa. Enquadrar um acontecimento significa, desse modo, atribuir um sentido a ele, definindo seus limites e seu significado e o encaixando em uma cadeia de sentidos anteriores, crenças, opiniões e convicções.

Estudando o enquadramento de discussões, Hample, Warner e Young (2008) sugerem a precedência da definição da situação como condição para a troca de mensagens: apenas quando se define o que está acontecendo, torna-se possível dar início à relação de comunicação. Dessa maneira, a compreensão de um determinado fato não é prerrogativa individual, mas ocorre em um tensionamento com os elementos aprendidos anteriormente, aptos a gerar uma determinada percepção. Por essa razão, no enquadramento noticioso, a compreensão de uma notícia como "real" depende em boa medida de sua adequação aos quadros de sentido de seus potenciais leitores.

\section{A construção dos enquadramentos no Le Figaro e Le Monde}

Nos estudos de jornalismo, o conceito de enquadramento vem sendo usado preferencialmente para identificar os direcionamentos na cobertura de fatos e eventos a partir das referências feitas nas próprias notícias. Encontra-se, dessa maneira, próximo de uma perspectiva referente à narração dos fatos, no sentido colocado por Sodré (2008) como forma de indicar uma leitura preferencial.

O enquadramento de um fato decorre do modo como ele é narrado. A indicação dos protagonismos, escolha dos atributos das personagens, a seleção de suas falas, as fontes ou fatos tomados como contrapontos, a inclusão ou omissão de determinados detalhes formam o enquadramento de um determinado fato.

No que se segue, a análise é individualizada de acordo com cada veículo. 
Enquadramentos midiáticos de Lula na imprensa francesa: uma análise do Le Monde e Le Figaro

Tabela 1. Enquadramentos identificados nas matérias do Le Figaro e Le Monde

\begin{tabular}{ll}
\hline Lula como um líder carismático & Le Figaro: 2 \\
& Le Monde: 5 \\
\hline Lula como um presidente que deixou o poder com alta & Le Figaro: 1 \\
popularidade/tirou o Brasil da miséria & Le Monde: 11 \\
\hline Lula como uma poderosa figura política brasileira & Le Figaro: 5 \\
\hline Lula como candidato às eleições de 2018 & Le Monde: 7 \\
\hline Lula odiado por parte da população brasileira & Le Figaro: 2 \\
& Le Monde: 4 \\
\hline Lula como possível culpado na Operação Lava Jato & Le Figaro: 2 \\
(comandante supremo do esquema) & Le Monde: 7 \\
\hline Lula como ídolo das classes populares & Le Monde: 7 \\
\hline Lula como alguém que polariza a população 1 \\
\hline Lula como ex-metalúrgico/ sindicalista & Le Figaro: 1 \\
& Le Monde: 12 \\
\hline Lula como mito/ícone & Le Figaro: 3 \\
& Le Monde: 5 \\
\hline & Le Figaro: 3 \\
& Le Monde: 13 \\
\hline & Le Figaro: 1 \\
& Le Monde: 13 \\
\hline
\end{tabular}

Fonte: elaboração dos autores

\section{(a) Le Figaro}

Ao utilizar a ferramenta de busca disponível no site do Le Figaro, identificamos sete matérias sobre a Operação Lava Jato que citam Lula no título: "Brasil: Lula suspeito de ter se beneficiado de 'favores' de empresas acusadas de corrupção" 1 , "Brasil: a sombra da justiça paira sobre o ícone Lula" 2 , "No Brasil, Rousseff e Lula se unem diante do escândalo" 3 , "Lula retorna ao poder em pleno escândalo político-judiciário" 4 , "Brasil: a investigação acusa Lula" 5 , "No Brasil, o ex-presidente Lula enfrenta seu juiz" 6 e "Brasil: Lula condenado, a presidência se afasta" 7 .

Os holofotes do Le Figaro voltaram-se ao ex-presidente brasileiro de forma acentuada a partir de 4 de março de 2016, quando Lula foi conduzido coercitivamente para prestar depoimento à

1. "Brésil : Lula soupçonné d'avoir bénéficié de «faveurs» d'entreprises accusées de corruption" - Publicada em 04/03/2016.

2. "Brésil: l'ombre de la justice plane sur l'icône Lula" - Publicada em 08/03/2016.

3. "Au Brésil, Rousseff et Lula s'unissent face au scandale" - Publicada em 15/03/2016.

4. "Lula revient au pouvoir en plein scandale politico-judiciaire" - Publicada em 16/03/2016.

5. "Brésil : le parquet accable Lula" - Publicada em 15/09/2016.

6. "Au Brésil, l'ex-président Lula fait face à son juge" - Publicada em 10/05/2017.

7. “Brésil: Lula condamné, la présidence s'éloigne" - Publicada em 13/07/2017. 
Polícia Federal, no aeroporto de Congonhas, em São Paulo. Os textos "Brasil: Lula suspeito de ter se beneficiado de "favores' de empresas acusadas de corrupção" e "Brasil: a sombra da justiça paira sobre o ícone Lula" tratam do assunto. O primeiro, de forma geral, fala sobre as acusações a Lula, destacando os manifestantes presentes no aeroporto durante seu depoimento e também aqueles que protestaram ao redor de sua residência, em São Bernardo do Campo, região metropolitana de São Paulo.

O segundo texto explica por que Lula foi conduzido coercitivamente e os motivos de sua figura estar passando por um momento de descrédito no Brasil. No texto, Lula é tratado como "figura da esquerda brasileira", "possível candidato em 2018" e comparado ao ex-presidente Getúlio Vargas.

Essa referência histórica pode ser associado ao que, em última análise, sugere Yang (2015): enquadramentos são responsáveis, a longo prazo, pela construção e consolidação de parte dos estereótipos em circulação na sociedade. Provocados ou acentuados pela apresentação midiática de um enquadramento específico, certas representações sociais são erigidas em termos de uma visão parcial e unilateral, formando um estereótipo midiático.

Além do interrogatório no aeroporto, o texto também compara Lula e Getúlio Vargas, dizendo que os dois são os Chefes de Estado mais carismáticos da República e que, tanto na época de Vargas como hoje, a sociedade está polarizada entre os que os amam e os que os odeiam. A reportagem diz que Lula é "aclamado entre os seus admiradores de esquerda" como o "guerreiro do povo" e também pela figura que representa e pelas mudanças sociais que fez no País, como a adoção do sistema de cotas nas universidades, o aumento do salário mínimo e a determinação de direitos trabalhistas para empregadas domésticas, que desagradou parte da elite brasileira.

A reportagem afirma que o discurso ético do PT "não faz mais sentido por conta de escândalos de corrupção nos quais o partido está envolvido" e diz que, assim como em 1954, época de Vargas, o papel da imprensa tem sido colocado em xeque no Brasil. O texto destaca que é necessário aplaudir os jornalistas que não se intimidam pelo título, carisma ou papel histórico do ex-presidente Lula, mas questiona e considera "caricatural" a narrativa na qual Lula e o PT são apresentados como "os maiores bandidos da história".

Na matéria "No Brasil, Rousseff e Lula se unem diante do escândalo", o assunto é a união entre Dilma e Lula para enfrentar as manifestações pró-impeachment e as acusações do ex-presidente na Operação Lava Jato. Para Dilma, ter Lula no governo como Ministro da Casa Civil "evitaria sua destituição", pois ele teria a chance de ajudar a negociar com os "barões do PMDB" o apoio à permanência da presidenta e também auxiliaria a corrigir a política econômica do governo, ajudando o País a sair da recessão. Já para Lula, o ministério poderia livrá-lo do julgamento na Lava Jato, ganhando imunidade ministerial e só podendo ser julgado pelo Supremo Tribunal Federal (STF).

O que era previsto aconteceu: Lula foi nomeado Chefe da Casa Civil no governo de Dilma Rousseff. A matéria "Lula retorna ao poder em pleno escândalo político-judiciário", explica que, no Brasil, esse cargo seria o equivalente ao de um "Primeiro Ministro" e que, ao aceitar esse papel, Lula viraria o "verdadeiro chefe do governo". Diz que Dilma mostrou "falta de aptidão" para fazer negociações políticas e que Lula teria a chance de "negociar com a base e mudar essa situação".

A matéria mostra que a situação de Lula era "bastante delicada" naquele momento: se ele conseguisse sucesso no seu papel de Chefe da Casa Civil, poderia salvar Dilma Rousseff do impe- 
achment; se falhasse, acabaria sujando sua reputação. Dois dias após assumir o cargo, a posse de Lula foi suspendida pelo STF.

O texto "Brasil: a investigação acusa Lula" ${ }^{8}$, escrito por Anne Vigna, dá voz tanto aos responsáveis pela Operação Lava Jato quanto à defesa de Lula. Para os primeiros, o ex-presidente é o "chefe da orquestra" de um sistema de corrupção, ligado tanto ao "Mensalão" (esquema de compra de votos de parlamentares) quanto à Lava Jato. Eles creem, mesmo sem provas, que Lula e seu partido PT têm um "objetivo triplo", que é "manter-se no poder", "assegurar o governo do País" e "enriquecer ilegalmente". Lula se defende dizendo que seus acusadores criaram uma espécie de ficção, dando poder a Michel Temer e tentando acabar com sua imagem.

A matéria mostra que Lula e o PT argumentam ser "perseguidos pela oposição", que está "construindo uma narrativa para destruí-los perante a opinião pública". Lula é enquadrado como alguém que "não se defende com provas de sua inocência", mas se "faz de vítima".

D'Angelo, Calderone e Territola (2005) mostram como as narrativas da cobertura eleitoral norte-americana se apresentam como uma série de enquadramentos, embora bastante nuançados, dos fatos e acontecimentos relacionados ao tema. O enquadramento, sugerem, não é estanque, e diversos quadros de sentido podem aparecer na cobertura, tanto em termos cronológicos quanto simultâneos.

A cobertura política parece ser um tema particularmente propício às pesquisas sobre enquadramento na medida em que a vitória eleitoral, nas eleições democráticas, não pode prescindir de um jogo estratégico de construção de uma imagem pública, dentro do qual o enquadramento de um fato ou de um candidato pode ser uma contribuição decisiva.

O texto "No Brasil, o ex-presidente Lula enfrenta seu juiz" 9 trata do "confronto" entre o expresidente e o juiz responsável pela Lava Jato, Sergio Moro. O depoimento de Lula é enquadrado como um "duelo entre as duas pessoas mais populares do País", onde, de um lado, está "um orador carismático de 71 e com uma vida política voltada às lutas sindicais", e, do outro, um juiz de 44 anos que "se recusa a ceder", "viciado em trabalho" e com uma vida "quase monástica". Lula é mostrado como alguém que ganhou popularidade ao tirar milhões de brasileiros da miséria e também como o possível favorito nas eleições presidenciais de 2018.

O último texto "Brasil: Lula condenado, a presidência se afasta" ${ }^{10}$, sobre a condenação do expresidente em primeira instância por Sergio Moro. Novamente Lula é mostrado como uma figura emblemática da esquerda e sua possível candidatura em 2018 é citada, além da oposição entre ele e Moro. O autor menciona como a Bolsa de Valores de São Paulo e o mercado econômico comemoraram a condenação de Lula, pois consideram que agora o "risco Lula" nas eleições de 2018 é mais fraco. Lula é enquadrado aqui como alguém "nocivo à economia do País" e rejeitado especialmente por setores da elite econômica brasileira.

8. "Au Brésil: le parque accable Lula" - Publicada em 15/09/2016.

9. "Au Bésil, l'ex-président Lula fait face à son juge" - Publicada em 10/05/2017.

10. "Brésil: Lula condamné, la présidence s'eloigne" - Publicada em 13/07/2017. 
Tabela 2. Exemplos de enquadramentos identificados nas matérias do site Le Figaro

Enquadramentos de Lula como um “Lula e Vargas são os dois chefes de estado mais carismátiícone brasileiro, como alguém que deixou um bom legado ao País e como um herói da população desfavorecida cos da história brasileira" - 08/03/2016

"Luiz Inacio Lula da Silva é um orador carismático de 71 anos, um político endurecido pelas lutas sindicais" $10 / 05 / 2017$

"O ex-presidente, que construiu sua popularidade liberando milhões de brasileiros da miséria durante seus dois mandatos (2002-2009), é hoje dado por muitos como favorito da próxima eleição presidencial" - 10/05/2017

"... amado pelos brasileiros pobres por ter feito milhões deles saírem da miséria" - 10/05/2017

Enquadramentos de Lula como um líder em descrédito, suspeito de corrupção na Operação Lava Jato e odiado por parte da população
"Fundador do Partido dos Trabalhadores (PT), o ex-presidente não é bem visto na sua própria região, onde há placas nas ruas que levam à sua residência que dizem "Residência do Lula bandido" ou "Lula na cadeia" - 04/03/2016

"Há anos não se via Luiz Inacio Lula da Silva expressar tal raiva" - 08/03/2016

"Será que a casa de Lula vai desmoronar?" - 08/03/2016

"O antigo presidente brasileiro Luiz Inacio Lula da Silva (2003-2010) seria o 'chefe da orquestra', o 'comandante supremo' do sistema de corrupção no seio da Petrobras" $15 / 09 / 2016$

"Os problemas do antigo presidente com a justiça não param por aí: ele é investigado em Brasília em quatro casos ligados à Lava Jato por tráfico de influência, corrupção passiva ou lavagem de dinheiro" - 10/05/2017

"A Bolsa de Valores e os mercados financeiros comemoraram a condenação do ex-presidente estimando que 'o risco Lula' para a eleição presidencial de outubro de 2018 tenha diminuído" - 13/07/2017

Fonte: elaboração dos autores

\section{(b) Le Monde}

O primeiro texto onde o nome de Lula aparece com destaque foi publicado em 4 de março de 2016, quando ele foi conduzido coercitivamente para depôr no Aeroporto de Congonhas. Sobre o tema, foram publicados quatro matérias: "O ex-presidente Lula tenta salvar sua reputação e o Brasil" "11, "No Brasil, o ex-presidente Lula pego pelo escândalo Petrobras" 12, "Brasil: Envolvido

11. "L'ancien président Lula tente de sauver sa réputation et le Brésil" - Publicada em 04/03/2016.

12. "L'ancien président Lula tente de sauver sa réputation et le Brésil" - Publicada em 05/03/2016. 
no escândalo Petrobras, o ex-presidente Lula convida seus partidários a apoiá-lo" 13 e "No Brasil, o ex-presidente Lula tenta evitar sua prisão" ${ }^{14}$.

Na linha fina do primeiro texto, Lula é abordado como "ídolo das classes populares". A notícia afirma que os vazamentos judiciais e o suposto envolvimento de Lula nesses escândalo político fazem com que ele "perca pouco a pouco sua reputação". Segundo ela, verdadeiras ou anedóticas, as denúncias demonstram como Lula não é mais intocável.

O texto descreve Lula como um senhor 70 anos que "venceu um câncer de garganta", "superou o escândalo do Mensalão", exerceu dois mandatos presidenciais "quase sem falhas" e, agora, pretende voltar ao poder disputando possivelmente as eleições de 2018. Ele é apresentado também como candidato ideal para o PT pelo seu carisma e pragmatismo. No entanto, para conquistar os eleitores decepcionados com o PT, teria que desassociar o seu nome ao de Dilma Rousseff, pois a aprovação do governo dela era bastante baixa, por volta dos $11 \%$.

Matthes e Kohring (2008) relacionam a análise de conteúdo como uma estratégia metodológica especialmente bem-vinda para o estudo dos enquadramentos noticiosos a partir de aportes diferentes em relação ao conteúdo, que incluem, mas não se limitam, à análise linguística e à hermenêutica. $\mathrm{O}$ enquadramento de uma notícia, ressaltam, não está circunscrito a um conjunto pequeno de referenciais cognitivos: ao contrário, parece existir uma intersecção entre diversos tipos de enquadramentos próximos no âmbito da construção da notícia, denominados pelos autores como um "aglomerado" (cluster) de enquadramentos.

A noção de aglomerado pode ser particularmente frutífera para a compreensão dos diversos enquadramentos observados neste trabalho, sobretudo quando se leva em consideração a coexistência de vários quadros de referência concorrentes em uma mesma notícia - por exemplo, a disparidade entre o enquadramento dos títulos quando comparados com o texto das reportagens em si. Nos casos analisados, foi possível notar um enquadramento mais próximo da dramatização da cobertura nos títulos das notícias, em contraste com uma cobertura mais nuançada no corpo do texto.

O texto "No Brasil, o ex-presidente Lula pego pelo escândalo Petrobras" fala das acusações envolvendo Lula e dá destaque à comoção dos apoiadores do ex-presidente logo após ele ter sido conduzido coercitivamente pela Polícia Federal. Lula é tratado como "defensor dos mais humildes" e, logo no início da matéria, militantes do PT que denunciam a perseguição dele como um "golpe de Estado" têm espaço, assim como o ex-presidente, que se defende no texto. A matéria o trata como "ofendido" e descreve seu discurso como "agressivo", atacando as autoridades, a mídia e a oposição.

Na matéria escrita quando Lula aceitou o convite para se tornar Chefe da Casa Civil do governo de Dilma Rousseff ("O retorno de Lula ao governo coloca o Brasil na rua" ${ }^{15}$ ), o politólogo Mathias de Alencastro diz que, caso tivesse sucesso em seu novo papel, Lula poderia se tornar um Charles de Gaulle. Já se houvesse fracasso, ele e Dilma Rousseff seriam como Vladmir Putin e Dmitri Medvedev, presidente e primeiro-ministro da Rússia.

13. "Brésil : rattrapé par le scandale Petrobras, l'ancien président Lula appelle ses partisans à le soutenir" - Publicada em 06/03/2016.

14. "Au Brésil, l'ancien président Lula tente d'éviter la prision" - Publicada em 11/03/2016.

15. "Le retour de Lula au gouvernement met le Brésil dans la rue" - Publicada em 17/03/2016. 
O texto se encerra afirmando que ter aceitado o cargo de Chefe da Casa Civil poderia comprometer a "aura" de Lula, recorrendo, mais uma vez, à porcentagem de aprovação de seu último mandato como presidente. A jornalista Claire Gatinois, que assina a maioria dos textos sobre o Brasil no Le Monde, escreve que, de qualquer forma, Lula já manchou sua reputação de estadista e prejudicou a sua admiração perante a imprensa internacional.

A relação de proximidade e confiança de Lula com a imprensa internacional pode ser percebida no texto "Lula em missão de sedução para defender Dilma Rousseff" ${ }^{16}$, sobre a coletiva de imprensa convocada pelo ex-presidente para defender a então líder do Brasil. O carisma de Lula tem destaque na linha-fina da matéria e também é citado em diversas partes da matéria. O texto diz que, na conversa com os jornalistas estrangeiros, Lula "emocionou a sala", "bateu o punho na mesa" e usou suas características metáforas sobre futebol para explicar a situação do País diversas vezes, dando à situação delicada do Brasil um "ar mais leve".

Lula é apresentado como alguém que acabou o mandato presidencial em 2010 com grande aceitação da população e deixou o País em uma situação próspera e promissora, mas que agora está afetado pelos escândalos de corrupção nos quais tem o nome envolvido.

O texto cita a fase em que Lula era considerado "Lulinha paz e amor", ou seja, quando abrandou seu discurso mais inflamado de sindicalista e conquistou a maior parte do apoio da população brasileira, e também fala sobre a desolação do ex-presidente ao assistir às manifestações que pediam o impeachment de Dilma. Nesse trecho, a narrativa aponta algumas brechas no discurso e nas atitudes de Lula, pois, outrora, ele era defensor do procedimento de destituição e atualmente refere-se ao impeachment de Dilma como um "golpe de estado", um procedimento sem fundamento jurídico.

As referências ao "paz e amor" ou "golpe de estado" sugerem o que Herkman (2016) mostra ao dizer que enquadramentos diferentes são responsáveis, também, pela atribuição de sentidos a certas expressões. Ele demonstra que, no campo da comunicação política, a compreensão de uma palavra, como "populismo", deriva dos quadros de sentido dentro dos quais a expressão aparece e é operacionalizada. Observe-se que não se trata de uma definição estritamente semântica, mas sobretudo pragmática.

Embora as denúncias das injustiças sofridas por Dilma Rousseff tenham sido o assunto principal da conversa com os jornalistas estrangeiros, o envolvimento de Lula na Operação Lava Jato e a sua relação conflituosa não deixaram de entrar na pauta. Ao ser questionado sobre as suspeitas de corrupção, Lula preferiu dizer que os seus advogados eram as pessoas mais preparadas para fazer a sua defesa, e aproveitou o momento para falar sobre as suas discordâncias com o juiz Sergio Moro, descrito como um "fanfarrão com jeito de cowboy" dirigido pela sua súbita notoriedade. Lula diz que Moro é um homem inteligente e competente, embora tenha cometido um erro ao tornar públicas as suas escutas pessoais, criando, assim, um circo midiático e um "espetáculo pirotécnico".

O texto "No Brasil, o ex-presidente Lula acusado de tentar obstruir a Justiça" ${ }^{17}$, publicado em julho de 2016, refere-se a Lula como "ícone do povo brasileiro" e "mito político". Ao resgatar

16. "Lula en mission séduction pour défendre Dilma Rousseff" - Publicada em: 29/03/2016.

17. “Au Brésil, l'ex-président Lula inculpé pour tentative d'entrave à la justice" - Publicada em 29/07/2016. 
esses dois conceitos, a jornalista coloca o político em um alto patamar por ter contribuído para tirar dezenas de milhões de brasileiros da pobreza. Uma das fontes do texto, o cientista político Carlos Melo, professor do Instituto Insper, diz que Lula é considerado como um "Deus" por muitos, mas que isso não tira a sua responsabilidade em oferecer explicações à Justiça. A matéria dá voz a uma fonte anônima, citada no texto como próxima ao PT, para dizer que as pessoas estão cansadas da situação e querem o fim dessa "telenovela".

Neste aspecto, o enquadramento de escândalos políticos é observado particularmente por Kepplinger, Geiss e Siebert (2011). Em seu estudo, os autores mostram como a associação entre um determinado político e um escândalo, gerada pelo enquadramento do fato, tende a estabelecer um protocolo de leitura em dois níveis. De um lado, a orientação cognitivo-racional que permite a compreensão, ainda que incompleta, do fato e, portanto, a ideia de que se está vendo "a" verdade naquilo que é reportado. De outro, o crescimento de atitudes emocionais em relação ao fato que transcendem a compreensão racional, tomando a forma de uma demanda por "punição" dos envolvidos.

O depoimento de Lula a Sergio Moro, em maio de 2017, foi enquadrado como um espetáculo político-midiático (Weber, 2011) pelo jornal Le Monde. A matéria "No Brasil, o show de Lula diante da justiça" ${ }^{18}$, mostra um embate entre o ex-presidente, representante do povo, e o responsável pela condução da Operação Lava Jato, símbolo da elite e guardião da democracia diante dos defensores da ética. A notícia sugere que, independente do resultado futuro, Lula "brilhou mais no depoimento" e acabou saindo como "vencedor". Segundo o texto, Sergio Moro, apesar de ter se tornado bastante popular por prender diversas figuras poderosas, "perde sua força" ao atacar Lula, que usa de seu carisma para "conquistar a opinião pública" e denuncia constantemente um "complô para impedi-lo de concorrer às eleições de 2018".

O político é enquadrado como alguém que tem grande conhecimento de estratégias retóricas e suscita tanto o ódio quanto a paixão da população, sendo aclamado e também vítima de vaias.

Percebemos que este texto oferece mais espaço a fontes favoráveis a Lula, como Gilberto Maringoni e Lincoln Secco, do que à oposição e também dá mais voz a especialistas em detrimento de fontes oficiais.

18. “Au Brésil, le « show » de Lula face à la justice" - Publicada em 11/05/2017. 
Tabela 3. Exemplos de enquadramentos identificados nas matérias do site Le Monde

\begin{abstract}
Enquadramentos de Lula como um ícone brasileiro, como alguém que deixou um bom legado ao País e como um herói da população desfavorecida
\end{abstract}

"Com 70 anos de idade, após cumprir dois mandatos, quase sem faltas, depois de ter vencido um câncer de garganta e superado o escândalo 'Mensalão', o homem parece pronto a entrar na disputa da eleição presidencial de 2018" - 04/03/2016 "Suas palavras, seu carisma, seu pragmatismo fazem dele o candidato do PT" - 04/03/2016

"O ícone da esquerda brasileira quer se mostrar combativo"06/03/2016

"Icône das classes populares" - 11/03/2016

"Aquele que permanece como o porta-voz dos mais humildes" - 11/03/2016

"Lula conserva um capital simbólico, politico e emocional muito forte" - 18/03/2016

"Um símbolo no Brasil" - 28/03/2016

"Diversas vezes ele bateu na mesa, emocionou a sala e, depois, a fez rir usando suas habituais metáforas futebolísticas para dar um ar mais leve à situação delicada do Brasil" 29/03/2016

"Luiz Inacio Lula da Silva usou sua veia de sindicalista e o seu charme natural para ajudar novamente Dilma Rousseff, ameaçada de destituição" - 29/03/2016

"Em 2002, a vitória de Lula foi aclamada como a chegada de François Mitterrand ao poder, em 1981. Com suas esperanças à esquerda e seus medos à direita. Mas o "muro do dinheiro"rapidamente compreendeu que o novo presidente não era um inimigo. $\mathrm{O}$ homem soube como defender os necessitados sem assustar os ricos" - 12/05/2016

"Aquele que deixou seu segundo mandato com uma popularidade de mais de 80\%" - 29/07/2016

"Um mito político no seu país por ter contribuído para tirar dezenas de milhões de brasileiros da pobreza" - 29/07/2016 "O ex-sindicalista à frente da luta dos trabalhadores na ditadura militar (1964-1985) ainda incorpora um mito. Uma lenda forjada pelo garoto do Nordeste que não finalizou o ensino fundamental, mas foi capaz de tirar da miséria milhões de brasileiros, sem tirar dos trilhos as contas públicas, atraindo tanto a simpatia de George Bush como de Hugo Chavez" - 14/09/2016

"Ícone da esquerda latino-americana" - 19/07/2017

"No dia seguinte a sua condenação, Lula mostrou-se combativo, gritando que 'ainda está no jogo' e exprimindo sua forte intenção de concorrer à eleição" - 19/07/2017 


Enquadramentos de Lula como um
líder em descrédito, suspeito de cor-
rupção na Operação Lava Jato e
odiado por parte da população

"Teremos, em breve, provas de que o ex-presidente, fundador do PT, anteriormente adulado, estaria também afetado neste caso sujo?" - 04/03/2016

"Estes vazamentos judiciais quase diários estão destruindo gradualmente a reputação do ídolo das classes trabalhadoras do Brasil. Reais ou fantasiosos, anedóticos ou embaraçosos, esses casos mostram que Lula, que deixou o poder com uma popularidade de $80 \%$, não é mais intocável"- 04/03/2016 "O animal político agora está irritado" - 04/03/2016

"A disgraça de Lula foi consumada? Ele levará o PT junto em sua queda? O homem superou muitas dificuldades desde que entrou na carreira política nos anos 80" - 05/03/2016 "Lula está muito, muito fragilizado" - 05/03/2016 "Lula, suspeito de corrupção, é o alvo da Operação chamada Lava Jato" - 17/03/2016

"Amado por $80 \%$ dos Brasileiros no final de seu último mandato, o homem poderá comprometer sua aura. Ao aparecer com atitude cínica e defensiva nas últimas semanas, ele já afetou sua reputação de estadista. Um homem que tirou da miséria mais de 25 milhões de brasileiros e que foi adulado pela imprensa internacional" - 17/03/2016

"Lula é hoje um homem prejudicado" - 29/03/2016

"O septuagenário está irritado. Ontem defensor do procedimento de destituição previsto na Constituição, ele usa hoje da retórica de 'golpe de Estado' para denunciar um processo sem fundamento jurídico a seu ver" - 29/03/2016

"Não importa qual seja o veredito, sua imagem e a dos grandes partidos políticos do Brasil já estão gravemente danificadas" - 20/09/2016

"Lula encontra-se implicado como um dos políticos mais odiados do país"- 14/10/2016

Fonte: elaboração dos autores

\section{Considerações finais}

Embora os jornais Le Monde e Le Figaro apresentem direcionamentos políticos distintos, os enquadramentos dados ao envolvimento de Lula na Operação Lava Jato não apresentam grandes distinções. Os feitos e a alta aprovação do ex-presidente em seus dois mandatos são constantemente resgatados, no entanto, tanto o Le Monde quanto o Le Figaro colocam diversas vezes em cheque a inocência de Lula nos casos de corrupção que vêm sendo desvelados pela Operação Lava Jato.

O enquadramento mostra o ex-presidente como alguém "amado" pelos mais pobres e "detestado" por parte da elite, que enfrenta de forma agressiva as acusações a que está respondendo. 
Identificamos também que os títulos das reportagens de ambos os jornais parecem ser mais chamativos, e, em certa medida, negativos, do que seu conteúdo propriamente dito.

Menashe e Siegel (1998) observam que o enquadramento de uma notícia parece se estabelecer como uma inferência a ser feita a partir do seu conteúdo, mas que, de certa maneira, não está necessariamente visível: é na observação dos direcionamentos, indicações léxicas, referências, proximidades e distanciamentos semânticos que o enquadramento, como parâmetro metacomunicacional, - revela-se.

Essa perspectiva sugere uma relação de continuidade entre o enquadramento de notícias e os quadros de sentido compartilhados pelos possíveis leitores, pois, ao sugerir um protocolo de leitura, busca ressonância e eco nos quadros da realidade.

Não se pode, no entanto, falar em "manipulação" deliberada de um acontecimento, embora isso possa acontecer eventualmente. A perspectiva de enquadramento está mais associada à ideia de "modos de narrar" e "modos de conhecer" do que ao conceito de uma distorção sistemática e planejada da realidade com vistas a quaisquer fins. Portanto, entende-se que o enquadramento é um processo necessário à compreensão do mundo na medida em que a complexidade do real se torna inteligível apenas a partir de sua redução às possibilidades cognoscentes de cada indivíduo. O enquadramento torna isso possível, mas ao preço da unilateralidade da experiência do fato, reduzido às categorias - os "quadros de sentido" de quem eventualmente estiver diante de uma versão.

\section{Referências}

Coleman, R.; Thorson, E. \& Wilkins, L. (2011).Testing the effect of framing and sourcing in health news stories. Journal of Health Communication, 16, 941-954.

D’Angelo, P.; Calderone, M. \& Territola, A. (2005). Strategy and issue framing: an exploratory analysis of topics and frames in campaign 2004 print news. Atlantic Journal of Communication, 13(4), 199-219.

David, C. et al. (2011). Finding frames: comparing two methods of frame analysis. Communication Methods and Measures, 5(4), 329-351.

Entman, R. (1994). Framing: toward clarification of a fractured paradigm. In M. Levy \& M. Gurevitch (ed.), Defining media studies. New York: Oxford University Press.

Goffman, E. (1974). Frame analysis: an essay on the organization of experience. New York: Harper.

Hample, D.; Warner, B. \& Young, D. (2009). Framing and editing interpersonal arguments. Argumentation, 23, 21-37.

Herkman, J. (2016). Construction of populism. Meanings given to populism in the nordic press. Nordicom Review, 37(special issue), 147-161.

Jasperson, A. (1998). Framing and the public agenda: media effects on the importance of the Federal Budget Deficit. Political Communication, 15, 205-224. 
Kepplinger, H. M.; Geiss, S. \& Siebert, S. (2012). Framing scandals: cognitive and emotional media effects. Journal of Communication, 62, 659-681.

Lecheler, S. et al (2015). The effects of repetitive news framing on political opinions over time. Communication Monographs, September, 82(3), 339-358.

Lecheler, S.; De Vreese, C. H. (2011). Getting real: the duration of framing effects. Journal of Communication, 61, 959-983.

Matthes, J. \& Kohring, M. (2008). The content analysis of media frames: toward improving reliability and validity. Journal of Communication, 58, 258-279.

Menashe, C. \& Siegel, M. (1998). The power of a frame: an analysis of newspaper coverage of Tobacco Issues - United States, 1985-1996. Journal of Health Communication, 3, 307325.

Pedersen, R. T. (2014). News media framing of negative campaigning. Mass Communication and Society, 17, 898-919.

Porto, M. (2004). Enquadramentos da mídia e política. In A. A. C. Rubim (org.), Comunicação e política: conceitos e abordagens (pp. 73-104). Salvador: Edufba.

Seo, K.; Dillard, J. \& Shen, F. (2013). The effects of message framing and visual image on persuasion. Communication Quarterly, November-December, 61(5), 564-583.

Thompson, J.B. (2002). O escândalo político: poder e visibilidade na era da mídia. Petrópolis: Vozes.

Yan, C.; Dillard, J.; Shen, F. (2012). Emotion, motivation, and the persuasive effects of message framing. Journal of Communication, 62, 682-700.

Yang, A. (2015). Building a cognitive-sociological model of stereotypes: stereotypical frames, social distance and framing effects. Howard Journal of Communications, 26, 254-274.

Weber, M. H. (2000). Comunicação e espetáculos da política. Porto Alegre: Ed. UFGRS. 